\title{
Money management and entrepreneurial training in microfinance: impact on beneficiaries and institutions
}

\author{
Lucia Dalla Pellegrina $^{1}$ (D) Giorgio Di Maio ${ }^{2}$ (D Paolo Landoni ${ }^{3}$ (D) \\ Emanuele Rusinà ${ }^{4}$
}

Received: 14 February 2020 / Accepted: 9 January 2021 / Published online: 4 February 2021

(c) The Author(s) 2021

\begin{abstract}
This study uses a randomized control trial to evaluate the outcome of integrating money management and entrepreneurial training into a microcredit program in India. We find positive and significant effects on clients' financial management skills and entrepreneurship abilities, particularly for clients with higher human capital, or more diligent, or having an entrepreneurial idea, and an increase in initiative and self-confidence. Effects appear stronger for clients obliged to attend the training course or more interested in attending it. By considering missed or delayed repayments reduction we assess the benefits of the training provided and of extending it for the institution.
\end{abstract}

Keywords Microfinance $\cdot$ Training program $\cdot$ Money management · Entrepreneurship

The authors wish to thank the Editor and two anonymous referees for precious suggestions and comments on the paper. We are indebted to Dr. Sujit Brahmochary, the Institute for Indian Mother and Child (IIMC) and the association Social Innovation Teams-Milano for their constant support throughout the research. The usual disclaimers apply.

Lucia Dalla Pellegrina

lucia.dallapellegrina@unimib.it

Giorgio Di Maio

giorgio.dimaio@mail.polimi.it

Paolo Landoni

paolo.landoni@polito.it

Emanuele Rusinà

emanuele.rusina@gmail.com

1 Department of Economics, Management and Statistics (DEMS), Università degli Studi di Milano-Bicocca, Milan, Italy

2 Department of Economics, Università degli Studi dell'Insubria, Varese, Italy

3 Department of Management and Production Engineering, Politecnico di Torino, Torino, Italy

4 University of California at Berkeley, Haas School of Business, Berkeley, CA, USA 
JEL Classification $\mathrm{G} 21 \cdot \mathrm{O} 15 \cdot \mathrm{L} 31 \cdot \mathrm{I} 25$

\section{Introduction}

Microcredit has gained significant importance in recent years as a mainstream development policy tool (e.g. Aagaard 2011; Guinnane 2011; Yunus 2004). The idea that poverty can be alleviated by providing easy and affordable access to credit and other financial services for low-income families has been widely supported in the literature (e.g. Bauer et al. 2012; Evans et al. 1999; Morduch 1999), although doubts concerning its impact remain (e.g. Angelucci et al. 2015; Attanasio et al. 2015; Augsburg et al. 2015; Banerjee et al. 2015; Copestake 2007; Crépon et al. 2015; Hermes and Lensink 2011; Imai et al. 2012; Karlan and Zinman 2011; Tarozzi et al. 2015).

As a strategy to support the microcredit sector, several microfinance institutions (MFIs) now offer a wide range of services, such as savings collection, microinsurance, and remittances (Armendáriz de Aghion and Morduch 2005; Churchill 2002; Hartarska and Parmeter 2009; Mata 2006). Moreover, business development services (BDS), such as financial literacy programs specifically aimed at improving the entrepreneurial skills of microcredit beneficiaries, are sometimes offered jointly with lending (Mortensen et al. 2005).

The general purpose of this study is to evaluate the impact of an entrepreneurial and money management training program conducted at the Institute for Indian Mother and Child (IIMC), a non-governmental development organization offering microfinance services in an extremely poor context. IIMC is headquartered near Kolkata, India. ${ }^{1}$

The outcomes of the training program were evaluated through a randomized control trial (RCT) to assess whether it brought tangible improvements in the business and cash flow management skills of the beneficiaries and net gains for the institution. Several microcredit beneficiaries were randomly assigned to either treatment or control groups; only the treatment group received the training during weekly afternoon sessions. A baseline survey was conducted before the intervention; a second survey was conducted 2 weeks after the completion of the course, while a follow-up survey was conducted 3 months later. In addition, the financial cash-flow data of both the treatment and the control group were analyzed over a period of 6 months after the experiment.

Difference-in-differences (DID) estimates suggest that the course had a positive and significant impact on the beneficiaries in the form of improved participation in household empowerment, working life, and enhanced money management skills, confirming the results of previous studies (Drexler et al. 2014; McKenzie and Woodruff 2014). In addition, the MFI could enjoy a substantially reduced number of missed or delayed repayments. The general analysis also provides a significant impact on business outcome measures. We found that more diligent attendees and those with higher entrepreneurial skills (higher human capital) were more likely to

\footnotetext{
1 At the time this study was conducted, the IIMC microcredit program sponsored seven village banks with 18,542 clients, all of which were women. The average loan disbursed was 5940 Indian Rupees (INR), with 8,215 loans disbursed per year; average deposits per person were INR 1155. The sustainability indicator of the IIMC Microcredit service (total income/total expenses) was 0.94 in 2010.
} 
leverage their ability in the form of changes in business activities and development of new products. Another novel outcome stemming from the investigation of borrowers' heterogeneities is the leverage effect exerted by training on the development of new businesses and products for the beneficiaries who already had an entrepreneurial idea before the beginning of the course.

Finally, we paid particular attention to the economic effects of the reduction in delayed repayments for IIMC. We calculated that the net cost of extending the program to the overall institution is about 43,000 USD.

This article is organized as follows. In Sect. 2, we outline the main contributions of the literature on the topics of financial literacy and RCTs in microfinance. Section 3 illustrates the details of the intervention and the experimental design. Section 4 describes the data and the estimation methods, outlining the hypotheses we intend to test. In Sect. 5, we present the results of the empirical analysis. In Sect. 6, we perform a cost-benefit analysis of the financial literacy program. Finally, Sect. 7 summarizes the main findings and concludes with policy recommendations.

\section{Literature background and differences compared to similar experiments}

Currently, MFIs are strongly recommended to offer BDS and technical assistance to loan beneficiaries in order to increase the odds of their projects' success and reduce default rates (Chowdhury and Mukhopadhaya 2012; Ledgerwood 1998). However, training programs have thus far been of extremely limited use due to MFIs' willingness to undertake massive cost reduction.

Microfinance clients perform a wide variety of business activities. For this reason, the training provided by MFIs usually focuses on improving general business skills rather than technical or sector-specific knowledge, as documented by McKenzie and Woodruff (2014). Bhatt and Tang (2002) instead claim that most training courses are indeed excessively general, which means that they frequently do not substantially improve the trainees' chances of success in conducting their own business. In some cases, borrowers even consider the training sessions to be a waste of time (Eversole 2003). However, Drexler, Fischer and Schoar (2014) find that a simple, rule-of-thumb based approach to training does better than a more formal training program, and improvements are significantly larger for micro-entrepreneurs who have lower skills or poor initial financial practices. The teaching basic skills, such as maintaining business records and separating household and business finances, appears as a necessary step for the development of "managerial capital", i.e., the organizational abilities required to manage an effective operational scale-up (Bruhn et al. 2010; McKenzie and Woodruff 2014).

The literature provides evidence that borrowers who are granted access to basic financial literacy can select profitable projects and/or generate more cash out of a specific activity (Godquin 2004). It has also been observed that sustained success in microfinance can depend on participants' literacy, numeracy skills, and microenterprise training (Coppock et al. 2011) and that better-educated entrepreneurs have a greater ability to understand and analyze complex information, resulting in more effective business decisions (Baklouti 2013; Bhatt and Tang 2002). 
Some studies have found little or no evidence of changes in key borrowers' outcomes, such as business revenues, profits, employment or household expenditure (Bruhn and Zia 2013; Khan and Ali 2014; Mahmud et al. 2014; Sayinzoga et al. 2016), especially when considering female clients (Berge et al. 2015; Giné and Mansuri 2014). However, the positive impact on business knowledge improvements and increased client retention rates for the MFIs providing formal training in business skills is widely assessed (Karlan and Valdivia 2011). Loan repayment rates also appear to be positively related to training (Roslan and Karim 2009). In particular, enhancing women's entrepreneurship and improving their financial management skills has become a priority for some microcredit providers (Afrin et al. 2008). Since they are generally poorer and less educated, it is unquestionable that women (especially those living in rural areas) are more in need of financial literacy and business training (Armendáriz de Aghion and Morduch 2005; Mayoux 2001) and are expected to better respond to it (e.g. Field et al. 2010).

Considering the empowerment effect of training itself, Ngo and Wahhaj (2012) suggest that women receiving complementary business training in an activity that requires their husbands' cooperation are more likely to benefit from access to credit than those who receive training in an autonomous productive activity that they can undertake independently within the household. There is also evidence suggesting that borrowing alone does not empower women (Alam 2012; Holvoet 2005). It is not by chance that the most successful microcredit programs are not confined to either credit provision or training, but offer a group atmosphere and a safety net in which women can share information and set up networks. Specialized business training taking place in groups is therefore considered crucial to this end (Mahmud 2003). All these features may also help women in becoming more independent and increase self-esteem and confidence. For example, Edgcomb (2002), Cook et al. (2001), and Dumas (2001) analyze MFIs offering integrated business development training, finding that the latter significantly improves microenterprise performance and generates microentrepreneurs' empowerment (Brau and Woller 2004). On the one hand, individual's networks are significant predictors of entrepreneurial activity and are particularly important in the early stages of the entrepreneurial process (Afandi et al. 2017). On the other hand, personal connections are very important for women in developing countries as a means to countervail an adverse social context (Poggesi et al. 2016).

Previous studies (Benzing et al. 2005a, b, c; Chu et al. 2007) reveal that motivations and success factors are important determinants of entrepreneurial behavior. Such behavior could strengthen the entrepreneurial spirit and empower women entrepreneurs in developing countries. Of particular relevance for our analysis is the fact that Karlan and Valdivia (2011) report a statistically significant, but quantitatively rather modest, improvement in business knowledge from the training, whereas they do not find effects on entrepreneurial skills.

The second module of the course sought to teach beneficiaries how to identify the strengths and weaknesses of their current business, how to address basic business problems, discover the most profitable market niches, and successfully reach customers. These improvements were intended to increase profits within the current business or represent a drive to establish new and profitable ventures. 
Our study builds on the experiment conducted by Karlan and Valdivia (2011) in Peru, and contains several specific features compared to the impact assessments of their and other educational programs. However, our study differs from the one of Karlan and Valdivia in several crucial respects, mainly regarding the social and economic context where our experiment has been conducted and the different lending policies of the MFI.

First, like Bjorvatn and Tungodden (2010), the implementation of our training program was carried out entirely by local resources. Operators involved in the experiment had a deep knowledge of the local context and were able to assist, monitor, and evaluate the participants' progress. They were not part of the microcredit program, whereas in Peru the credit officers provided the training to the MFI's clients. We chose the former operating methods to create a pleasant and supportive learning environment, which is considered to positively affect training outcomes (Huang 2003; Saeed and Zyngier 2012; Williams and Williams 2011).

Second, and related to the above, we could measure interest and effort throughout and after the experiment. Whereas Karlan and Valdivia (2011) measure interest in the training program by statements made by the entrepreneurs prior to training (which we also do), we also assessed interest in learning after the course. We considered the interest in a free (low interest) or costly (high interest) training declared by women before the course as an indicator of their motivation to learn, which is considered to have an important influence on the effectiveness of training (Garaus et al. 2016; Noe 1986). If the course was successful, we expect it to have boosted the motivation of women to receive further training.

We also measured attendance to the course, and effort and initial human capital by grading home assignments. Furthermore, attending the course was mandatory for the Women Peace Council (WPC) ${ }^{2}$ members but voluntary for non-members of WPC. These features allow heterogeneous treatment effects on business knowledge and other outcomes of interest to be investigated, even in their changes over time. We briefly summarize the main differences between the two experiments in Table 1.

In the following sections, the impact of the course on beneficiaries will be analyzed on a wide number of indicators.

\section{Experimental design}

\subsection{Institutional context}

IIMC offers microfinance services, microcredit and micro-savings collection, ${ }^{3}$ and social programs such as medical care, a health promotion program, an education and child sponsorship program.

IIMC's microcredit program is dedicated to married (or widowed) women. To enter the program, they must give proof of their permanent residence in their village

\footnotetext{
2 This program aims to provide social, cultural and intellectual support to poor village mothers. See next section for details.

3 See Mirpourian et al. (2016) for details on the microcredit program at IIMC.
} 
and they also need their husbands' permission. Groups' formation process starts with IIMC credit managers visiting villages where potential groups can be created, mostly in rural areas.

After the completion of the baseline training, IIMC's field officers select women and create groups of a maximum of 25 members. After 3 months of saving commitment, each woman can ask for a first loan of at most 3000 rupees, provided that she has an amount of at least 1/10 of the loan size in her savings account. After the first loan is disbursed, savings are not mandatory anymore, although IIMC carefully monitors its customers' saving balance and encourages continuous saving accumulation.

Each credit group attends weekly meetings where the clients repay the loan installments and deposit their savings to IIMC. The clients have to repay the loan within 1 year. They are expected to start the repayment after 1 month, with a total number of weekly installments equal to 44 . Each client is responsible for the repayment of her loan only because there is no joint responsibility. Compared to joint responsibility, individual responsibility leads to less peer-pressure in the microcredit group.

In addition, because of a strong social service orientation, the debt collection mechanism at IIMC is not built on short-term coercive methods and sanctions, widespread in the microfinance sector, but rather on tolerance and persuasion, as in some other MFIs (see for example Feigenberg et al. 2013; Hung 2003; Solli et al. 2015; White and Alam 2013).

Client retention is not a concern for IIMC because the demand for its microcredit program exceeds its supply capacity. True defaults are not common, but long delays are recurrent. These characteristics of the IIMC microcredit, combined with the fact that the institution also provides other services in the field of education and health, ensure that relations between IIMC and its clients can develop in an atmosphere of trust and collaboration. Consistently with this approach, we did not impose sanctions for non-participation in the training sessions.

\subsection{Set up of the experiment}

The training course took place within the meetings of the WPC Program. A WPC is composed of borrowers from the IIMC microcredit program. ${ }^{4}$ They meet regularly 5 days a week for $2 \mathrm{~h}$. In $2 \mathrm{~h}$ they concentrate on reading newspapers and magazines and watching television or video clips. From these media, they gather important social and economic information and discuss issues in light of how they are affecting women's rights and how issues could be resolved peacefully for the benefit of all, especially rural women. The rest of the day they visit, mostly in groups, walking around to observe happenings and meet people to socialize and listen to their problems. $^{5}$

\footnotetext{
4 The borrowers involved in the experiment belonged to four IIMC branches, namely Hatgacha, Chakberia, Kalyanpur and Hogolkuria, located in the South-East rural neighborhoods of Kolkata, West Bengal.

5 https://iimcmissioncal.org.
} 
Table 1 Main differences between the IIMC experiment and the experiment conducted by Karlan and Valdivia (2011)

This study
Context: IIMC-Kolkata (India)
Extremely high illiteracy rate that characterized
the beneficiaries of our experiment (about $25 \%$ ).
The course structure and teaching methods were
adapted in order to cope with communication
problems

Women are scarcely emancipated, also due to religious constraints. They do not have own economic activity, rarely they are allowed to work in their husbands' businesses

IIMC applies group lending methodology with individual liability

Lower interest rate $(20 \%)$

The institutional policy of IIMC is not built on short-term coercive methods and sanctions, but rather on tolerance and persuasion

Small-scale pilot experiment

Shorter length of the experiment (5-6 weeks, weekly meetings), longer training sessions (all afternoon)

Training sessions separate from Microfinance Program center meetings

The experiment relies on local staff to carry out the experiment. This allows a more accurate monitoring of the subjects involved

No sanctions were imposed for non-participation in the training sessions

\section{Randomization at the WPC level}

Detailed information regarding individual diligence and human capital of the beneficiaries was collected (rate of attendance at the individual level, course homework grades)

Allows to go in depth with the investigation of some aspects that did not respond to the stimulus of entrepreneurship training in other similar RCTs

Evaluates the net cost of extending the program to the overall institution

\section{$\mathrm{K} \& \mathrm{~V}$}

Context: FINCA-Ayacucho and Lima (Peru)

Relatively low illiteracy rate (about $2 \%$ in Lima and $15 \%$ in the Ayacucho region). The course followed similar guidelines as other educational training programs

Women are relatively emancipated, several of them autonomously run their own business activity

FINCA applies group lending methodology with joint liability

Higher interest rate $(84 \%)$

The institutional policy of FINCA follows standard debt collection practices

Large-scale experiment

Longer length of the experiment (1-2 years), shorter training sessions (30-60 min)

Training sessions during Microfinance Program center meetings

The experiment relied on the administrative network and resources of the microfinance program

Absences from or tardiness to the lessons were fined and could lead to exclusion from access to microcredit

Randomization at the bank-branch level

Individual course attendance was tracked but not used in the empirical analysis; dedication to the study was not tracked

Does not allow to gage subjects' interest in undertaking entrepreneurial activities before the experiment

Does not precisely quantify the net cost of extending the program to the overall institution

We selected the 16 WPCs taking part in the experiment by applying a geographical criterion to avoid discrepancies in the level of welfare that characterizes households living in different areas of Kolkata. This also allowed for transport costs to 
be minimized and enhanced the monitoring activities. ${ }^{6}$ We randomly selected eight WPCs to receive the treatment and we set the other eight as control.

We deliberately decided not to operate a randomization at the bank-branch level for two main reasons. First, given the compulsory attendance at WPC meetings, it was easier to extend the compulsion requirement to a share of participants in the training experiment and to distinguish them from volunteer attendees (see below). Second, there was a willingness to avoid selecting people from the same microcredit group for either the treated or the control experimental sample. Instead, members of a WPC may belong to different microcredit branches and-even if they are in the same branch - they often meet at different meeting points.

We involved in the experiment all members of the selected WPCs, 108 women, either as part of the treated group or as part of the control group. In particular, we admitted to the training program with compulsory attendance a randomly chosen group of 59 women. The other 59 women were surveyed without receiving any training.

Similar to Karlan and Valdivia (2011), to verify the role of motivation on the outcome variables, we integrated the original sample of 118 women with 55 volunteers. These were part of the microcredit program at the time of the experiment (like the women of the WPCs). They came to learn about the course from the IIMC officers who announced the start of the training experiment at the meetings of the microcredit program. All women who expressed a willingness to participate in the experiment were admitted and filled out the questionnaires on the baseline and assessment characteristics, although only those randomly selected to join the treated group of WPC women attended the course. Precisely, we randomly assigned 23 of these women to the treatment group and the remaining 32 to the control group. Finally, we assigned the volunteers belonging to the treated group to the treated WPC closer to their house for attending lectures. Overall, treated and control groups consisted of 82 and 91 members, respectively, for a total number of participants of 173 . We had to drop one treated-WPC woman from the database because more than fifty per cent of her responses to the survey were missing, remaining with a final sample of 172 women.

\subsection{Timing of the intervention}

The experiment was conducted throughout 2010. The course occurred in February and March. All the participants taking part in the experiment were surveyed at three points in time. A baseline survey (C1) was handed out before the course at the beginning of January (T1), prior to the assignment to either treated or control groups. A second questionnaire (C2) was submitted 2 weeks after the completion of the course at the end of March (T2). In this wave of the survey, we intended to measure participants' improvements in entrepreneurial and money management capabilities in the short term, i.e., acquired during the training program. A follow-up survey

\footnotetext{
${ }^{6}$ All WPCs active at the time of the experiment, apart two located at a very far distance from the IIMC headquarters were involved in the experiment, either as treated or non-treated units.
} 
(C3) was distributed 3 months after the completion of the course, at the end of June (T3), to test the persistency of the competences acquired and to evaluate the effects on institutional outcomes and household behaviors.

The financial data (F3) collected at IIMC were recorded in the group registers, and no digitalized information was available. Individual financial prospects were scanned and coded at the IIMC microcredit branch offices. Data cover the timespan from the beginning of the training (T1) to the end of the follow-up period (T3), although records on savings have been collected for a longer time-span, including months prior to the baseline survey (see next section). The timeline of the intervention is reported in Fig. 1.

\subsection{Course contents}

The lessons were developed taking into account the specific peculiarities of the local context. ${ }^{7}$ In particular, due to the extremely high illiteracy rate that characterized the beneficiaries of our experiment, we had to adapt its structure and teaching methods in order to cope with communication problems.

Under the most genuine rule-of-thumb approach (Drexler et al. 2014), trainers made use of posters, drawings, skits and tales to the largest possible extent to allow for the full participation of the illiterate segment of the groups. One of the main challenges of the training staff has been to scale down the course contents, to make borrowers aware of the consequences of financial mismanagement, particularly with respect to their personal lives. A chance was taken to stress that credit dependency-very usual in our context (Krishnaswamy 2007; Pujari 2011; Rajeev et al. 2012; Sajjad and Chauhan 2012) - is a negative element, and how to quantify the amount needed to make a reasonable and efficient loan application.

The course was divided into two distinct modules. The first one focused on money management, and the second one focused on entrepreneurship training. The five lessons that comprised the course covered the following broad topics: loan use; profit and basic accounting; reinvesting profits, savings, and separating money; problems, solutions and innovations; new business development. Each lesson was followed by a homework assignment that concentrated on the topics covered during the lesson and had to be completed with data concerning actual or projected expenses, revenues, and other financial variables of the beneficiary's household. ${ }^{8}$

Specifically, Lesson 1 focused on the correct use of the loans obtained, and on the consequences of using the loan for personal consumption or paying the instalments

\footnotetext{
7 Contents for the training course were developed with the support of the Indian Institute for Training and Development, the Indian Institute of Management in Kolkata, Freedom From Hunger, The Rural Finance Learning Centre of the United Nations, and the Community Empowerment Collective Society. As in other similar pilot programs, the teaching material of Freedom from Hunger (FFO) was used to shape the course contents. However, in our case the training staff adapted both the contents and the teaching methods to match the literacy standards of the trainees. The use of role plays, the business plan exercise, and all home assignments have been drafted specifically by the trainers for this program.

8 Appendix 2 describes in detail the course contents. Appendix 4 provides an example of home assignment.
} 


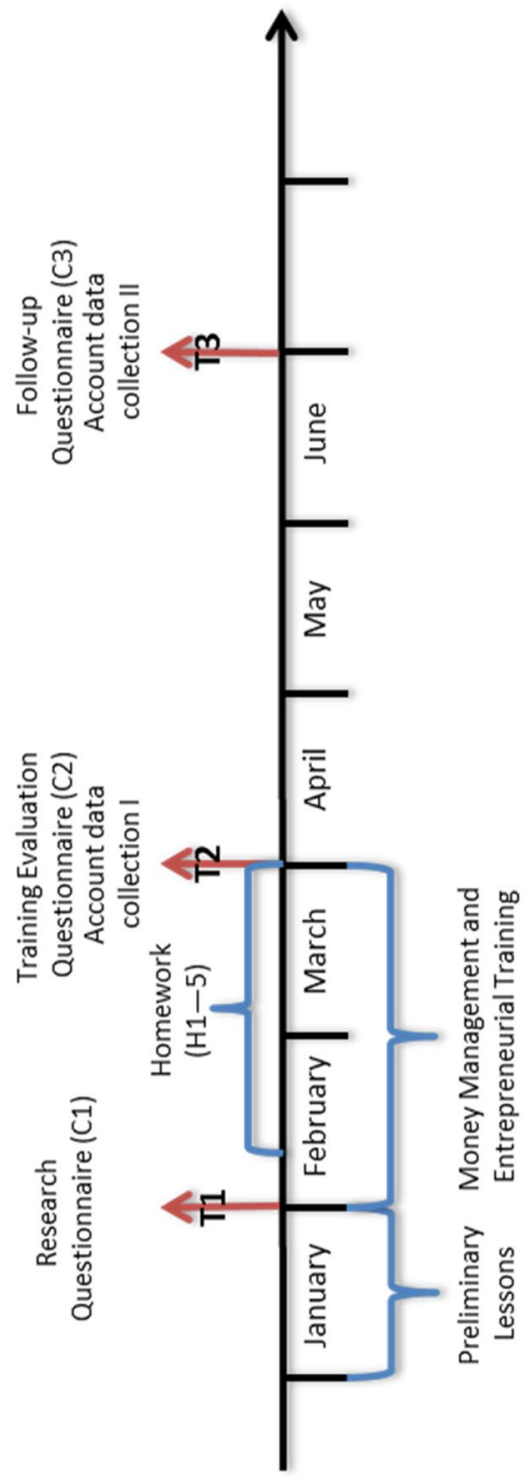

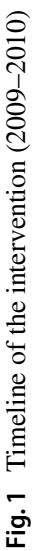


with the loan itself without any investment. The choice to introduce these points in the first lesson was dictated by the fact that local staff informed us that a large number of IIMC borrowers normally used most of the loan for purposes other than investment. Lesson 2 concentrated on the importance of keeping track of income and expenses at the household level, and on the calculation of one's own profit. The principle of separating the money was stressed through a tale that showed how a Bengali woman can be conscious of her expenses in every field by dividing them among different colored boxes (Cash-Box System). This system, in particular, allowed her to observe the evolution of her business by reinvesting funds, without making use of other household resources. Lesson 3 introduced the core of money management key principles. The money division system was extended introducing the possible use of loans to give a growth impulse to the business. The same tale of Lesson 2 was repeated, introducing the use of loans, the concept of reinvesting the profits, and the importance to accumulate savings. In this lesson women also learnt how to quantify the loan amount needed for their business, in order to avoid any form of credit dependency. Lesson 4 moved from the concept of money management to the one of (small-scale) entrepreneurship. Women were asked to describe the problems frequently occurring in specific businesses, then a discussion regarding the possible solutions followed. This was aimed at instilling a critical view towards their activities, along with the practice to ask advice to third parties (such as Microcredit officers, suppliers, and customers). Lesson 5 was designed to encourage the beneficiaries to examine new working opportunities in the nearby area and to analyze their feasibility in a wide range of aspects. Women were requested to point out the pro and cons of each working alternative. A role play was organized with the scope to identify the most adequate and profitable working possibilities in the area. The last lesson had also the purpose of motivating the attendees to exploit the microcredit service to start a new small-scale business.

The training team was composed of one main teacher helped by a group of assistants involved in preparing the material and performing the most dynamic part of the lectures, such as role-plays. They were supported by the IIMC staff, especially for reasons related to the need to translate from English to the local language. The team remained unchanged throughout the course and held all lectures, moving from one WPC to another over the week.

For the purpose of this analysis, it is important to stress that no other policy changes, such as the introduction of new initiatives at the individual WPC level, or variations in the microcredit program occurred along with the training.

\section{Empirical analysis}

\subsection{Data}

The main data sources of the study are financial data about the beneficiaries (F3) and the three questionnaires $(\mathrm{C} 1, \mathrm{C} 2, \mathrm{C} 3)$, as well as the homework grades (H1-H5). As mentioned previously, F3 includes information on loan disbursement, repayments, savings and withdrawals, collected by the credit managers during the microcredit 
group meetings. Collection of financial data occurred some months after the end of the course and included all the beneficiaries' financial transactions with IIMC from November 2009 to June 2010. The three surveys (C1, C2, C3) consisted of a variety of questions about demographic characteristics, household financial variables, and business practices ${ }^{9,10}$. Table 2 provides a description with summary statistics of the variables considered for the evaluation of the impact of the intervention, along with other baseline characteristics that will be used as covariates. ${ }^{11}$

Though the randomization process is expected to take care of the imbalances between treatment and control groups, the disproportion of non-WPC clients in the two groups may be responsible for the differences in some baseline mean values, because WPC members are generally poorer than non-WPC ones (the volunteers), and less empowered. The volunteers, instead, can be considered the "average" of women taking part in the microcredit program. In particular, although differences in household income and expenditure are not statistically significant, disparities among the baseline values of the outcome variables are observed in monthly repayments, interest in costly training, profits calculation, and opportunity to make decisions within the family, which can be indicative of the control group's wealthier and more empowered conditions. We will discuss proxies to assess a common trend of these variables in the remainder of this section. For most of the covariates, $t$ tests do not reject the hypothesis of equal means, except for the last loan amount, possibly indicating that larger loans are accorded to wealthier borrowers. ${ }^{12}$

\subsection{Hypotheses and methodology}

The first hypothesis we aim to test is whether the course, based on a rule-of-thumb approach, had the effect of improving money management practices. This is the expected outcome of teaching basic accountancy principles, such as keeping track of expenses and income, calculating profit, determining how much to reinvest in the business, how much to save and how much to use for personal consumption, which were taught in the first module of the training program (H1, Table 3$)$.

In addition, we aim to test whether the course had effects on some final outcomes. We expect that the correct adoption of money management practices led to more careful planning of the household's cash flows. This could have eventually induced more timely repayment of the loan and improved participants' economic outcomes, such as income and savings (H2-H3, Table 3$)$.

\footnotetext{
9 See Appendix 3.

${ }^{10}$ The women belonging to either the treated or control groups conducted similar business activities. In particular, the computed frequencies corresponding to each activity do not show evidence of substantial discrepancies between the two groups (see Appendix 1, Table A1.2).

11 Table A1.1 in Appendix 1 contains a full description of all the variables used in the analysis.

12 Despite some differences being relatively low in magnitude (e.g., for last loan amount the difference is 1,497 rupees more for the control group, which is approximately EUR 17 or USD 21) we accounted for these imbalances privileging DID (including covariates) over Simple Difference analysis. In Appendix 1 we provide robustness check using different specifications of the estimated regressions (see next section).
} 


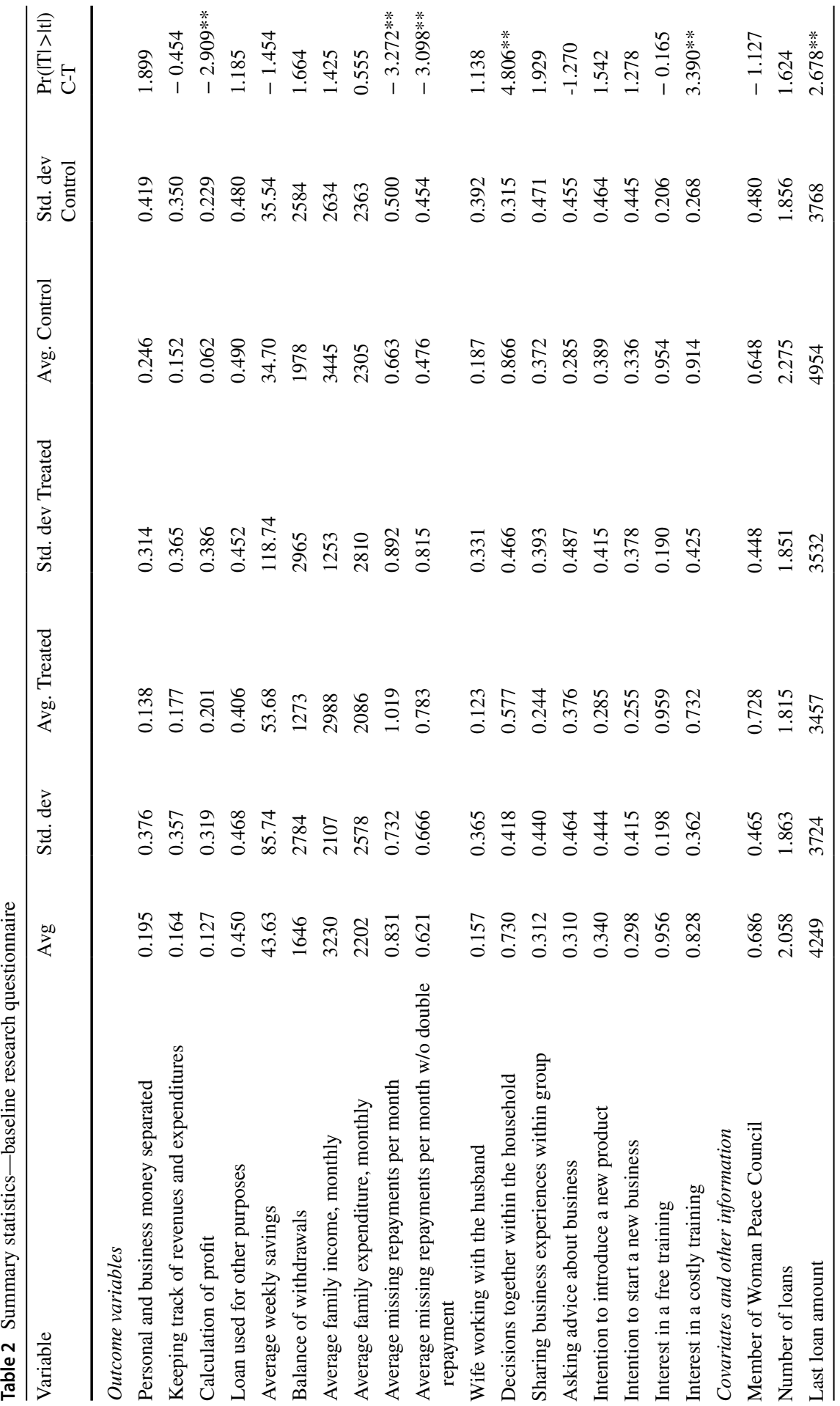




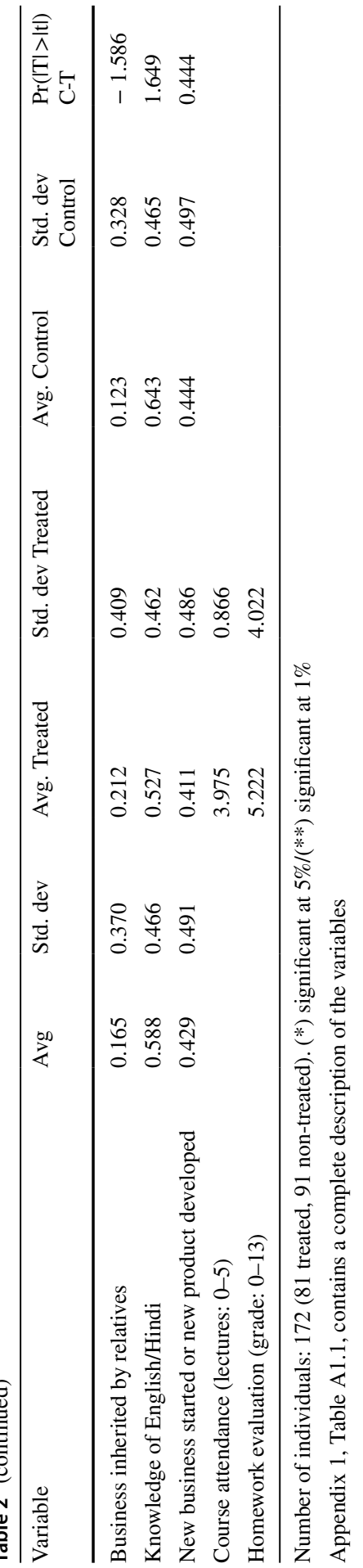


Table 3 Variables used to evaluate the effectiveness of the training

\begin{tabular}{|c|c|}
\hline Hypothesis & Variables \\
\hline $\begin{array}{l}H 1 \text { : The course improved money management prac- } \\
\text { tices }\end{array}$ & $\begin{array}{l}\text { Personal and business money separated } \\
\text { Keeping track of revenues and expenditures } \\
\text { Calculation of profit } \\
\text { Loan used for other purposes }\end{array}$ \\
\hline$H 2$ : The course improved participants' outcomes & $\begin{array}{l}\text { Average weekly savings } \\
\text { Balance of withdrawals } \\
\text { Average family income, monthly } \\
\text { Average family expenditure, monthly }\end{array}$ \\
\hline H3: The course improved loan repayment performance & $\begin{array}{l}\text { Average missing repayments per month } \\
\text { Average missing repayments per month w/o } \\
\text { doubled repayment }\end{array}$ \\
\hline H4: The course empowered participants & $\begin{array}{l}\text { Wife working with the husband } \\
\text { Decisions together within the household } \\
\text { Sharing business experiences within group } \\
\text { Asking advice about business }\end{array}$ \\
\hline $\begin{array}{l}\text { H5: The course strengthened participants' entrepre- } \\
\text { neurship }\end{array}$ & $\begin{array}{l}\text { Intention to introduce a new product } \\
\text { Intention to start a new business }\end{array}$ \\
\hline H6: The course improved interest in training & $\begin{array}{l}\text { Interest in a free training } \\
\text { Interest in a costly training }\end{array}$ \\
\hline $\begin{array}{l}\text { H7: Compulsory attendance provides better results } \\
\text { than voluntary attendance }\end{array}$ & Regression analysis on sub-samples of attendees \\
\hline $\begin{array}{l}\text { H8: Previous interest in training improved the effect } \\
\text { of the course }\end{array}$ & Regression analysis on sub-samples of attendees \\
\hline $\begin{array}{l}\text { H9: Higher homework grades or greater attendance } \\
\text { (higher human capital) is a stimulus to undertake } \\
\text { new entrepreneurial activities }\end{array}$ & Regression analysis on sub-samples of attendees \\
\hline
\end{tabular}

We also expect women who have participated in the course to be more empowered in their family and to be more confident in their relationships with other women (H4, Table 3).

Furthermore, we aim to test whether the course strengthened participants' entrepreneurship, and in particular their intention to introduce new products or services or to start a new business ( $H 5$, Table 3); and whether the course was a stimulus to attend further training (H5, Table 3$)$.

Finally, we test a set of additional hypotheses, such as: whether compulsory attendance provides better results than voluntary attendance (H7, Table 3$)$; whether higher previous interest in training improved the outcome of the course $(H 8$, Table 3); and whether high human capital (higher attendance rate and better homework grading) improved the effect of the course ( $H 9$, Table 3 ).

The empirical methodology uses DID estimates to testify the above hypotheses. Defining $y_{i t}$ as the outcome variable for individual $i$ at time $t$, Treated ${ }_{i}$ as a dummy variable taking the value of 1 if the individual received the treatment and 0 otherwise, Post $_{t}$ as a dummy variable taking the value of 1 in the post-treatment 
period and 0 in the pre-treatment period, we performed estimations on the following equation:

$$
y_{i t}=\beta_{0}+\beta_{1} \text { Treated }_{i}+\beta_{2} \text { Post }_{t}+\beta_{3} \text { Treated }_{i} * \text { Post }_{t}+\varepsilon_{i t}
$$

We performed all regressions by using OLS, ${ }^{13}$ both in the baseline version and including covariates to increase the explanatory power of the model. Robust standard errors are used.

Defining a pre-treatment trend for the several dichotomous dependent variables was impossible due to the on-the-spot nature of the answers and the limited timespan available before the first round of the survey. On the other hand, obtaining more than two rounds of interviews helped reduce the importance of the assumptions regarding trend patterns and to test possible ambiguities or contradictions. We tested the presence of a common trend relying on borrowers' saving status, for which information is available for a lengthier period before the beginning of the training program (i.e., from April 2009) from borrowers' financial prospects. An F-test was performed on the differences between the treatment and control groups from time to time before the training to verify the hypothesis of their equality. ${ }^{14}$ None of the F-statistics rejects the hypothesis of constant difference between the control and the treatment group, so we can assume a common trend for savings prior to the intervention. Thanks to the high correlation with other institutional and financial measures (e.g., missing repayments, withdrawals, family income and expenditures) we are confident that the hypothesis of common trend can reasonably be extended to all other dependent variables.

\section{Results}

Table 4 reports the outcome of the DID estimates regarding the effects of the training program, i.e., the coefficients $\left(\beta_{3}\right)$ associated with the interaction term Treated $_{i} *$ Post $_{t}$ of Eq. (1) for several regressions, including covariates. ${ }^{15}$ Covariates consist of participation in WPC (compulsory/voluntary attendance), number of loans, last loan amount, business previously owned by relatives and knowledge of English language. Col. (1) and (2) show the results obtained by analyzing the full sample, with the differences computed between January and March 2010 and between January and June 2010 respectively. ${ }^{16}$

\footnotetext{
13 When the outcomes are binary, we estimate the effects using a Linear Probability Model (LPM). Textbook concerns about functional form misspecification for the LPM does not apply to impact estimation since treatment status is a binary variable (e.g. Angrist and Pischke, 2008).

${ }^{14}$ F-tests on the pattern of savings prior to the training is reported in Appendix 1, Table A1.3.

15 In Appendix 1, Tables A1.7 and A1.10-A1.12 show the results of these regressions also excluding covariates (col. (1) and (5)).

16 We also performed power t-tests (Cohen 1965; Fagley 1985; Fagley and McKinney 1983; Pallant 2001; Sawyer and Ball 1981) for all the estimated outcomes with statistical significance lower than $10 \%$. When the estimated effects with statistical significance lower than $10 \%$ indicated power higher than $80 \%$ we considered the results as indicative of a non-rejection of the null hypothesis of no difference in means between the treated and the control groups. Almost all the significant effects turn out to be estimated on adequate sample size with power above 80\%. For the baseline regressions, see Table A1.7 (caption), Appendix A1.
} 


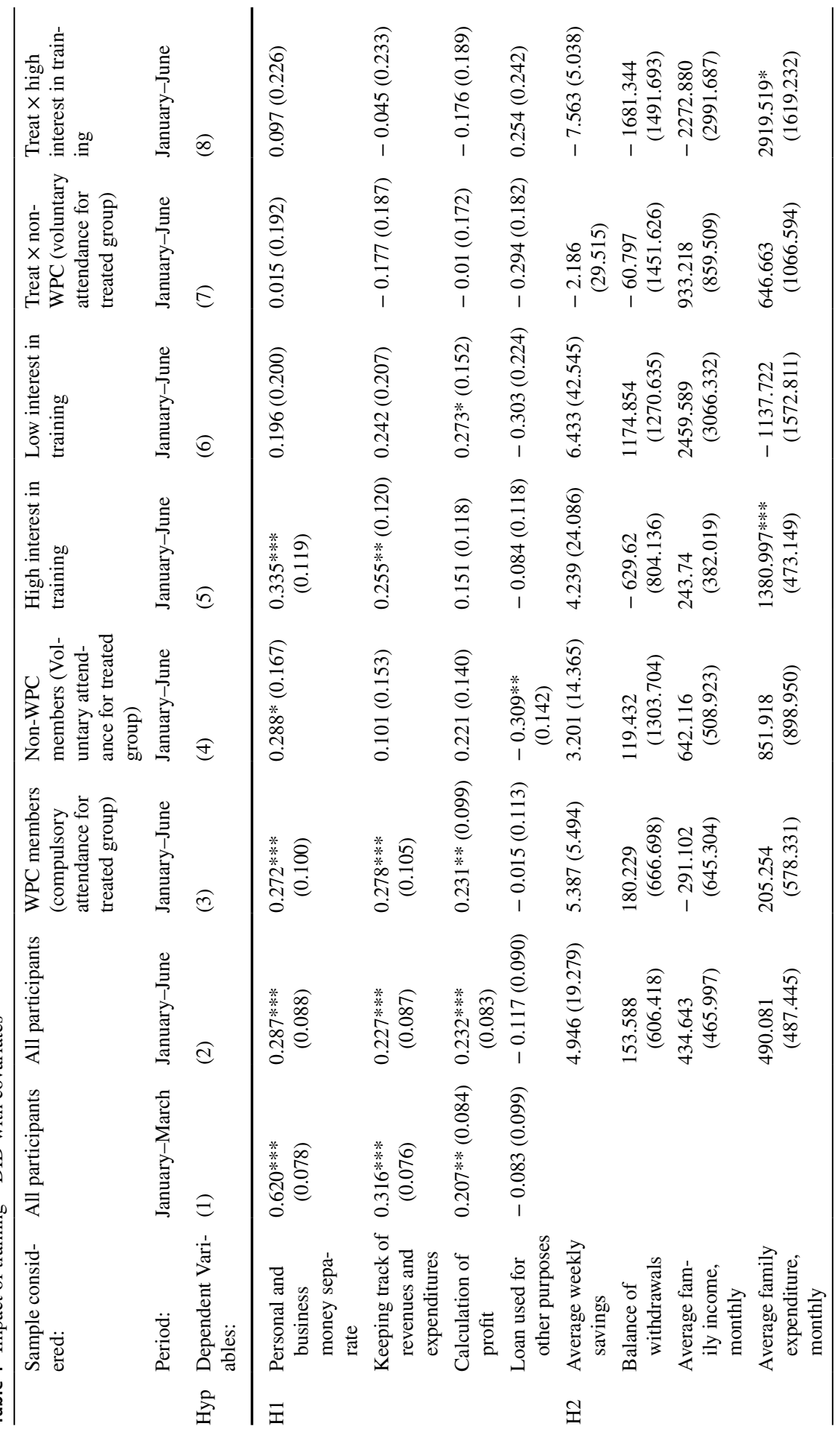




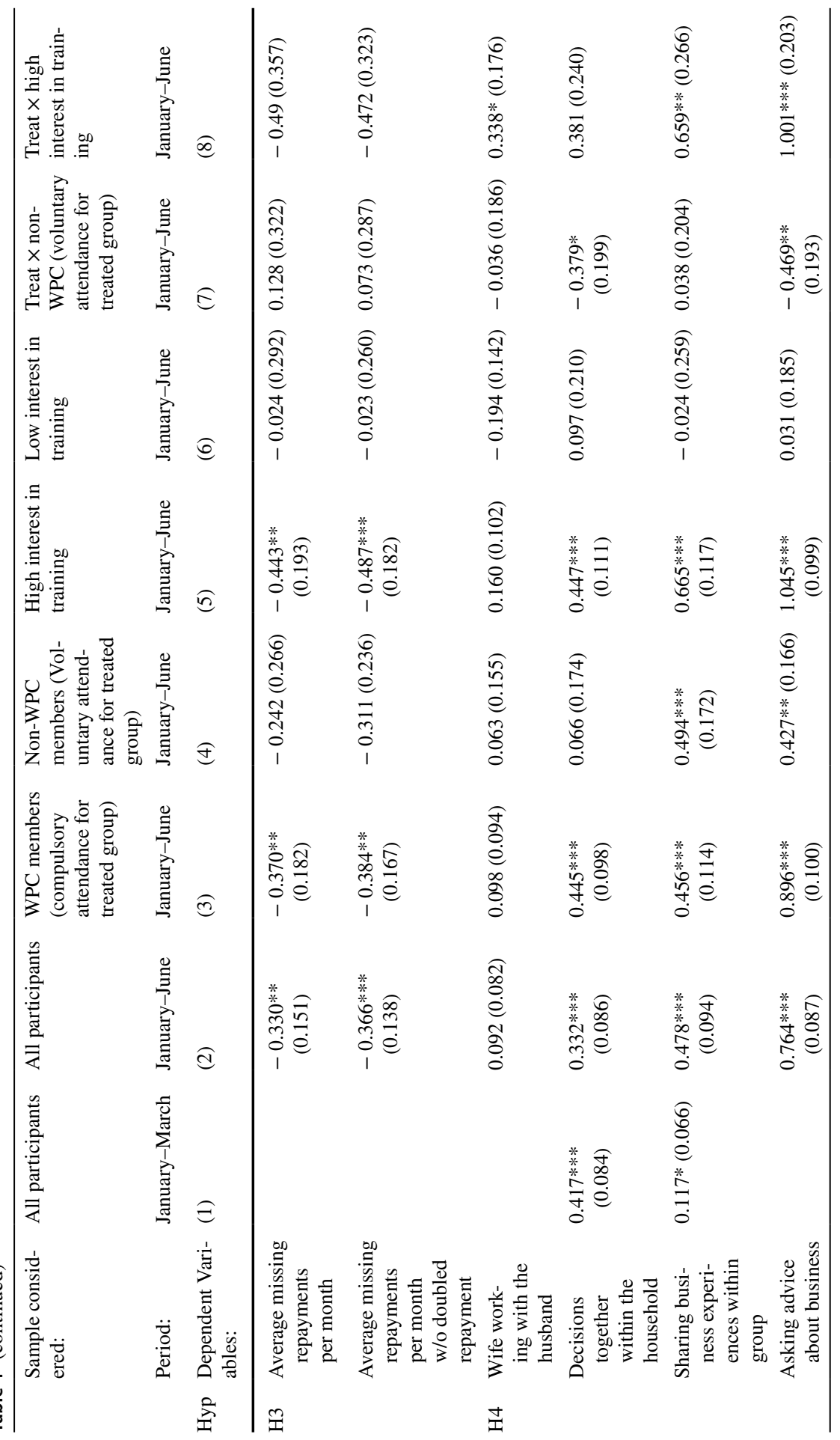




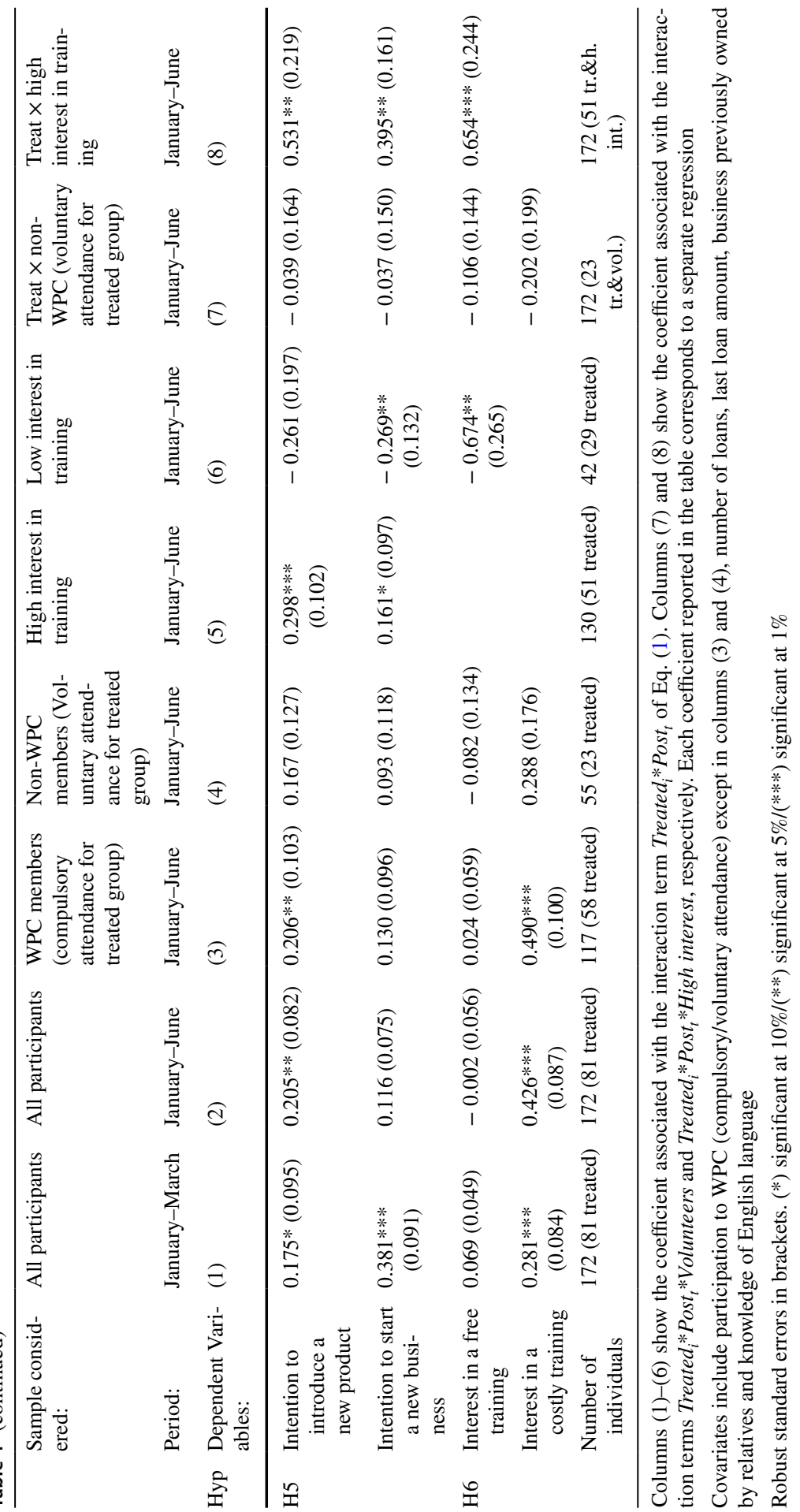




\subsection{Money management practices}

The results (col. (1) and (2)) suggest a substantial positive impact of the training on money management practices, especially regarding the calculation of profit, basic principles of separating personal and business money and keeping track of revenues and expenditures.

These results are consistent with hypothesis $\mathrm{Hl}$ and the findings of previous studies (de Mel et al. 2014; Karlan and Valdivia 2011; Mano et al. 2012; McKenzie and Woodruff 2014; Valdivia 2015).

There is instead no significant evidence of a reduction in the share of borrowers who use loans for purposes other than business activities. Loan-drift is common among poor households (about $45 \%$ of the women declare they use the money for non-productive purposes, Table 2). Qualitative interviews testified, however, that recipients normally use the loan for unexpected events, such as medical expenses or ceremonies, whereas they rarely use borrowed money for personal consumption. ${ }^{17}$ It is important to note that not only the course stressed the importance of using loans for business activities, but also IIMC constantly reiterates this message. The absence of a significant result suggests that treated women sincerely reported the changes that occurred after the course.

\subsection{Participants' economic outcomes}

Results relating to personal and household economic outcomes (col. (2)), such as savings, withdrawals, income and expenditure, show that the experiment has not been effective in modifying households' revenues and/or consumption habits. These results are not consistent with hypothesis $H 2$ but consistent with the findings of previous studies (Berge et al. 2015; Giné and Mansuri 2014). One possible explanation for this result is that real constraints hamper business outcomes, such as revenues and profits, and personal consumption and savings decisions. Improving women's money management and entrepreneurial skills seems unable to overcome these constraints, at least in the short term. This result seems to confirm that substantial improvements in the outcomes of income-generating activities carried out by women, on the verge of subsistence entrepreneurship, require a higher level of intervention on the economic and social conditions of the context in which they operate (Bruton et al. 2015; Neal 2017).

\subsection{Loan repayment performance}

Estimates (col. (2)) provide evidence that the course had the strong positive effect of improving loan repayment performance. In particular, it should be noted that the

\footnotetext{
17 However, there seems to be evidence of lack of power on the outcome related to the use of loans for non-productive purposes (see Appendix 1, Table A1.7), so we cannot definitely assess that the effects are non-significant.
} 
average missing repayments per month at the time of the experiment were 0.831 (Table 2), whereas the average number of due repayments should be 4.35 per month, meaning that $19 \%(0.831 / 4.35)$ of the installments were not repaid at the due date but were delayed. An estimated effect of -0.330 implies that post-treatment average delayed repayments become $11.5 \%(0.501 / 4.35)$. Similar effects are estimated excluding double repayments. ${ }^{18}$ These results are consistent with hypothesis $H 3$ and, in general, with the findings of some previous studies (Chowdhury and Mukhopadhaya 2012; Karlan and Valdivia 2011; Ledgerwood 1998; Roslan and Karim 2009). Better repayment performances can be the effect of improved money management practices by women but also of their greater willingness to show trustworthiness to the institution that provided the course.

\subsection{Empowerment}

Another interesting effect of the course is on the observed impact on decision making within the household (col. (1) and (2)), as the associated parameter is strongly significant and positive. This result is consistent with hypothesis $H 4$ and previous findings in the literature (Cook, Belliveau and Von Seggern 2001; Edgcomb 2002; Dumas 2001). However, we cannot explain this result, as Karlan and Valdivia (2011) suggest, with improved business success because we did not find positive and significant economic outcomes. We may suppose that women became more empowered in their families either because they showed greater competence or confidence or because they acquired a greater status for having participated in the course.

The estimated effect of the course is also positive and significant on the variables relating to empowerment in social relations. In particular, sharing business experiences within the group (col. (1)-(2)) and asking advice about business (col. (2)) turn out to be significant and with the expected sign, especially in the followup period. For the short-term effects (col. (1)), however, the impact on seeking business advice cannot be tested due to lack of sufficient answers in the first training evaluation questionnaire. These results are consistent with hypothesis $\mathrm{H} 4$ and suggest that the women felt safe to express themselves with their classmates. As indicated by Cajiao and Burke (2016), this perception of psychological safety can have further contributed to the effects associated with course design. The supportive environment provided by IIMC, in particular with its debt collection mechanism built on tolerance and persuasion rather than on short-term coercive methods and sanctions, and by combining microcredit with other social programs, may have contributed decisively to this result. Indeed, a pleasant atmosphere and a supportive environment have a key role in enhancing learners' motivation (Huang 2003; Saeed and Zyngier 2012; Williams and Williams 2011). Interestingly, Karlan and Valdivia (2011) do not find an empowerment effect of the training in their study of a pure microfinance institution that applies a much stricter policy.

\footnotetext{
18 It is possible to avoid negative consequences on future loans' conditions by doubling the repayment the following week, when one repayment is missing.
} 
This result also suggests that the course allowed women to develop a greater interaction with each other than they had previously developed within microcredit groups and, in general, that it is possible and convenient to intervene actively to facilitate the internal dynamics of microcredit groups.

\subsection{Entrepreneurship}

Regarding the impact of training on entrepreneurship, the results (col. (1) and (2)) are less clear. The intention to start a new business increased at the end of the course, but this intent rapidly decreased in the following months. The intention to introduce new products, already present at the end of the course, significantly improved in the follow-up period. These results are not fully consistent with hypothesis $H 5$, but are consistent with the results of Karlan and Valdivia (2011). The course seems to have stimulated a passing intention that women have only partially realized. This result also can be the effect of real difficulties present in the IIMC context and suggests the need for supporting women who intend to introduce innovations in their businesses. These aspects will be further explored in the next sections.

\subsection{Interest in training}

The results (col. (1) and (2), Table 4) show that the interest in another free training course of the same kind did not vary in a significant way, although the participants in the course became much more motivated to pay for further instruction. However, low power ${ }^{19}$ seems to be a serious concern, especially in light of the fact that the treated group expressed its willingness to bear the cost of further training. Hence, there is partial evidence on the fact that H6 may hold. We will deserve more indepth investigation also to these features.

\subsection{Robustness check}

\subsubsection{Differences in baseline characteristics}

Table 2 shows that the balancing properties for some baseline characteristics of the treated and control groups do not hold. The problem appears serious because significant differences are observed on some variables that are also the main target outcomes of the experiment (such as missed repayments).

In order to provide robustness to the empirical evidence illustrated in the previous section, we supplemented the analysis with further regressions to show that the main results are robust to different specifications of the estimated equation. First, as standard practice, we performed Simple Difference regressions with baseline values of

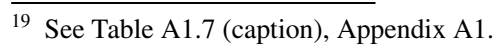


the dependent variables to account for initial discrepancies between treated women and those in the control group. Second, and most relevant, we checked whether these baseline differences are likely to interact with treatment by including also an interaction term between the baseline values and the treatment dummy. In particular, we assume that a non-significant interaction term excludes the possibility that the observed disparities may affect the estimated treatment effects.

Estimates show that almost all the parameters associated with the interaction term are indeed not significant. ${ }^{20}$ We conclude that the observed post-treatment outcome for the treated subjects is not affected by the initial disparities, and that these differences were probably due to the larger presence of WPC women in the treated group, ${ }^{21}$ or random and due to the small-scale of the experiment. ${ }^{22}$

\subsubsection{ANCOVA}

Following the indications from David McKenzie (2012) ${ }^{23}$ and related discussion with other scholars, we considered an ACOVA model. Since dependent variables are sometimes correlated, ${ }^{24}$ ANCOVA should provide more efficient estimates than OLS. Results do not provide substantial differences compared to the previous estimates. ${ }^{25}$ In particular, estimated parameters are quite similar to those obtained using baseline DID, whereas efficiency gains are limited.

\subsubsection{Principal component analysis (PCA)}

A common concern with studies testing multiple hypotheses is that there are many outcomes tested at the same time, which increases the chances of false positives. For this reason, we conducted a Principal Component Analysis to construct representative measures for each of the six hypotheses H1-H6. We obtained Factor 1-Factor 6, the main principal components. Regressions, reproducing those described in the previous sub-sections were performed using factors from PCA, rather than the full set of outcome variables. Results, reported in Table 5, are in line with the main analysis, confirming that all the hypotheses hold, except $H 2$ related to the attendees' economic outcomes, saving, and consumption habits.

\footnotetext{
${ }^{20}$ Refer to Appendix A1, Tables A1.7 and A1.10-A1.12, col. (3), (7), (4a)-(4b) and (8a)-(8b) for Simple Difference regression outcomes. In particular, parameters associated with the interaction term between the baseline value of the dependent variables and the treatment dummy are in col. (4b) and (8b).

${ }^{21}$ If the differences are due to the poorer condition of WPC women, F-tests based on the pattern of savings in the pretreatment period (see Sect. 4.2) should be a proxy for a common trend in wealth as well.

${ }^{22}$ Addressing the problem of unbalanced properties between treatment and control samples by adopting an interaction strategy does not represent a formal test for endogeneity. Nevertheless, combined with lack of power for some estimations this goes in the direction of bolstering the results, supporting evidence in favor of causal identification.

${ }^{23}$ See more details at https://blogs.worldbank.org/impactevaluations/another-reason-prefer-ancova-deali ng-changes-measurement-between-baseline-and-follow

${ }^{24}$ See correlation matrix in Table A.1.8.

${ }^{25}$ Refer to Appendix A1, Table A1.9
} 


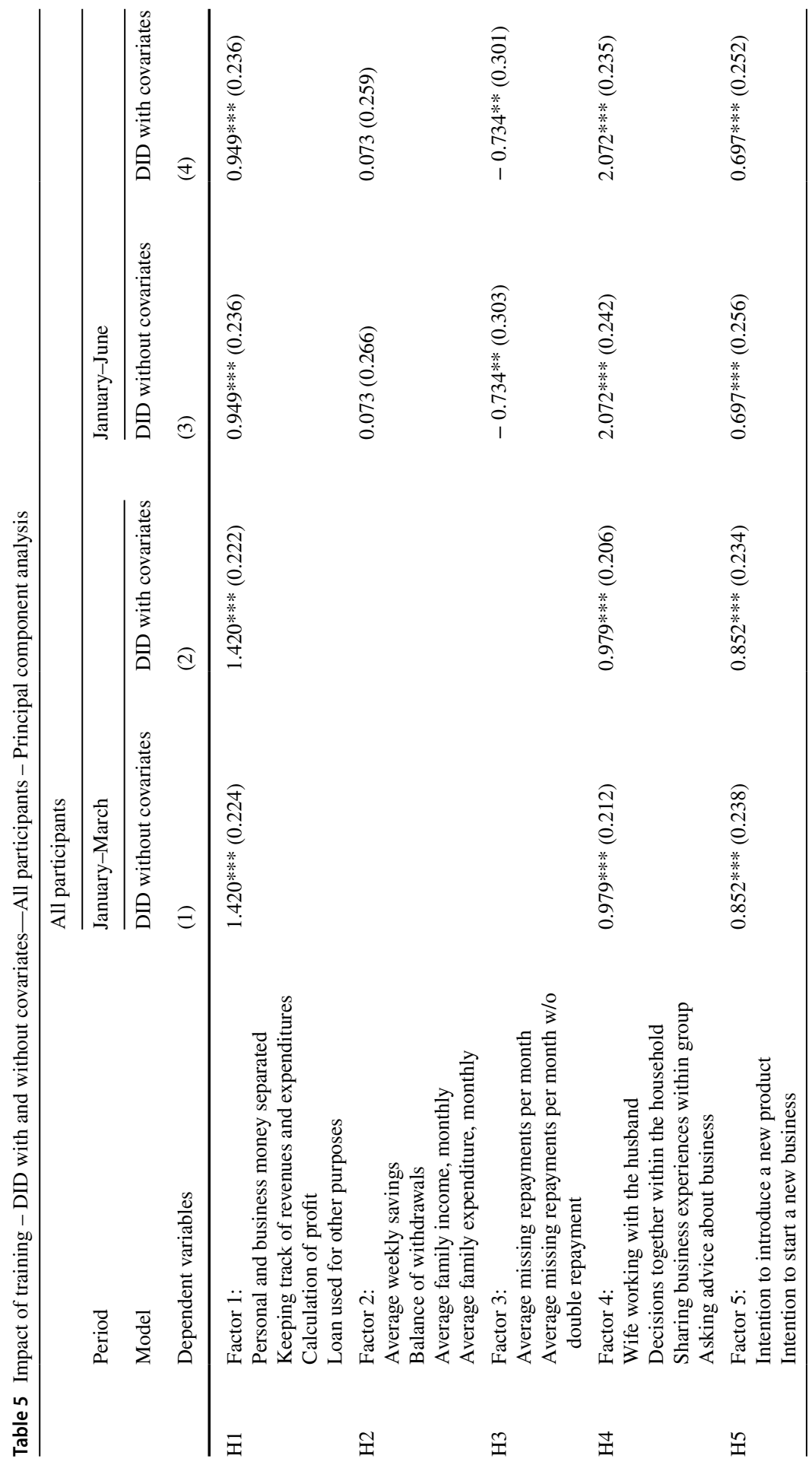




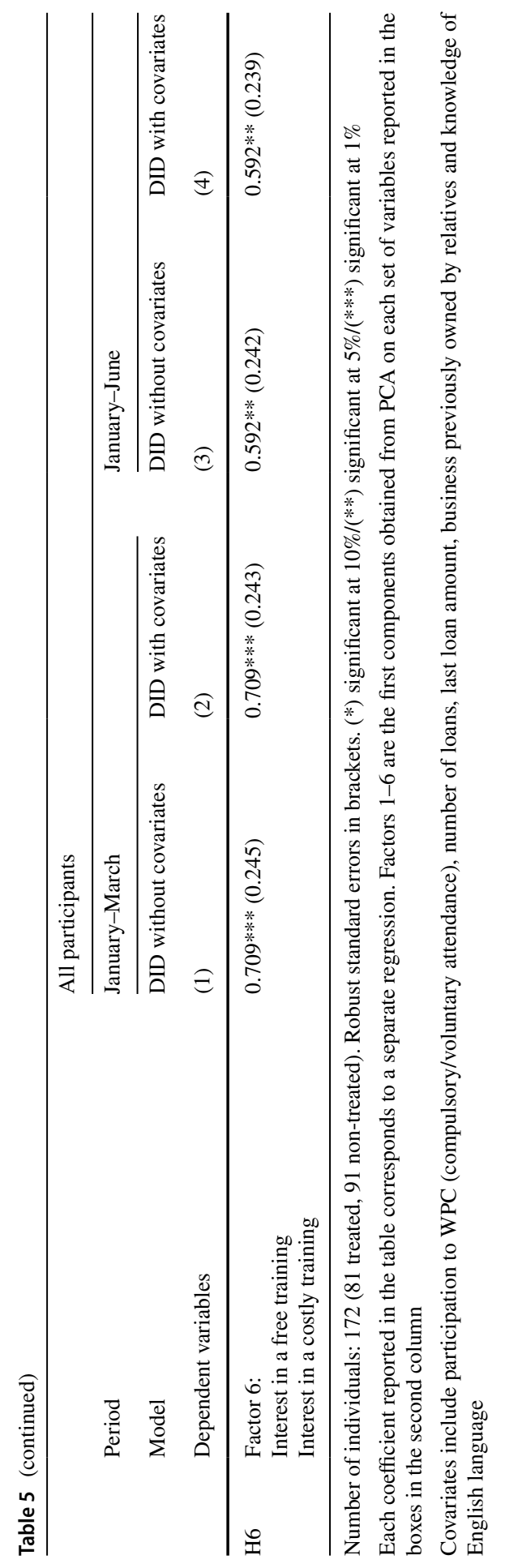




\subsection{Further empirical evidence}

\subsubsection{Compulsory vs. voluntary attendance}

Focusing on the possible different effects of the training on participants for whom attendance was compulsory (treated WPC members) versus volunteers (microcredit borrowers non-WPC members) (Table 4, col. (3) and (4)), ${ }^{26}$ it can be immediately concluded that the former found much greater advantage from the course. This result is consistent with hypothesis $H 7$. Specifically, compared to non-treated WPC members, treated WPC members improved significantly their money management practices and repayment performances, as well as their empowerment, both within and outside the household. Instead, compared to untreated volunteers, treated volunteers only reduced the practice of using the loan for purposes other than those related to their business.

\subsubsection{High interest in training vs. low interest in training}

We compared borrowers who at the beginning of the course declared a high interest in entrepreneurial training, i.e., their intention to pay a small amount for a course, versus those who had a low interest, i.e., declared to be only interested in a free course (Table 4, col. (5) and (6)). ${ }^{27}$ Estimates provide evidence that the group with previous interest in costly training is likely to achieve significant improvements in several fields. In particular, treated women among this group are likely to reduce missing repayments, increase interest in starting new businesses, and became more empowered. This confirms that $H 8$ holds specifically for this subset of attendees.

The outcome associated with the increase in monthly spending for the group with the greatest interest in paying for future training probably reflects the fact that it is the richest women who want to support such kind of investment.

\subsubsection{Attendance and interest}

Considered altogether, women who have been required to compulsorily attend the course and those who were initially willing to pay for the training have been the ones who benefited the most from this opportunity.

However, given the positive correlation (17\%) between the status of WPC affiliate and the willingness to pay for training, we opted for contemporaneously including the interaction terms treatment-voluntary and treatment-interest in the regression in order to see if one effect prevails over the other.

\footnotetext{
${ }^{26}$ See t-tests for differences in means on these sub-groups in Table A1.4 and additional regressions in Table A1.10 (Appendix 1).

27 See t-tests for differences in means on these sub-groups in Table A1.5 and additional regressions in Table A1.11 (Appendix 1).
} 
Although non-randomness prevents us from making any considerations regarding the causality mechanisms undergoing between the treatment applied to some particular categories of borrowers and the outcome variables, the results may be useful for providing indications in terms of either focusing more on the selection of the attendees or promoting stronger discipline during the program to maximize its effects. The results are reported in col. (7) and (8) of Table 4.

As is evident from the higher significance of some of the parameters in col. (8) (compared to col. (7)), the willingness to participate in a costly training seems to overcome the difference in impact between the women required to attend and the volunteers. The most significant effects of the treatment are observed on empowerment variables, such as joining the husband's work, asking business advice, and sharing work experience with peers. It is also noteworthy that treated women who showed more interest in further training became more interested in developing new products and starting new business activities. An increase in monthly expenditure is also confirmed.

Overall, the empirical evidence suggests that to stimulate the learning process, the empowerment level of the beneficiaries, and their entrepreneurial skills, the MFI should concentrate more on selecting those who show more interest in learning. Indeed, the empirical evidence in col. (7) and (8) suggests that the mandatory participation requirement does not seem to be a key factor in determining the success of the program.

\subsubsection{Leverage effects of training on entrepreneurial ideas: diligence, homework grades, and human capital}

As in previous teaching experiments of business practices (Karlan and Valdivia 2011), the analyses conducted so far provides limited insights regarding the ability of the course to stimulate the start-up of new businesses and the development of new products. In this section, our purpose is to shed light on these aspects exploiting heterogeneities among the borrowers. Information on whether new activities started in the period spanning from the end of the course to 3 months later is available from the follow-up survey submitted in June. ${ }^{28}$

Given these details, our first aim is to understand whether the program had the effect of encouraging those participants who had some projects in mind before attending the course to persevere in trying to implement their ideas. Our second purpose is to verify whether the course has been supportive in helping the participants with a higher level of human capital during the course (those who have shown greater diligence and achieved higher homework evaluation) to realize their intents.

As for the first aim, two relevant questions were asked before the start of the course. The first question is whether the respondent had the intention to start a new

\footnotetext{
${ }^{28}$ Due to the low number of responses obtained regarding the actual development of new products, compared to those relating to the start-up of new businesses, we opted for bundling the two responses. Consequently, the dependent variable is a dummy that takes value 1 if the respondent has declared that either she started a new business or she developed a new product.
} 
business, while the second is whether she had the intention to develop a new product. Combining the responses, which capture the borrowers' intentions, with the information on whether they succeeded in implementing new activities afterwards, may shed light on the possibility that the program has been successful in encouraging those who had valuable entrepreneurial ideas to insist on pursuing their initial objectives.

We used a linear model to estimate the relationship between borrowers' baseline characteristics and the intention to either start a new job or develop a new product for the control group. Then, we generated the predicted values of the variables "Intention to start a new business" and "Intention to introduce a new product" for the overall sample to obtain the probability of having "potentially" successful projects, net of the possible effects of being selected among the treated group. Finally, we interacted these predicted variables with the treatment dummy to estimate whether the program succeeded in turning good ideas into real investments.

The results are reported in the upper part of Table 6 . The estimates provide evidence that the training program significantly helped women who had the intention to start a new business and to develop new products to persevere.

As for the second purpose, we completed a similar exercise using the information on the grades achieved by the attendees in homework assignments, including the quality of their business plans, as a measure of entrepreneurial skills, ${ }^{29}$ and women's class attendance rates ${ }^{30}$ as a proxy of their diligence throughout the course. ${ }^{31}$ Our purpose is to evaluate whether the program succeeded in separating high-skilled and diligent attendees from low-skilled and less diligent ones, and whether training helped the best ones to start new projects and/or products.

Contrary to large-scale experiments, a small-scale RCT allowed us to grade all home assignments and the attendees' business plans, as well as to keep track of their attendance rates. Obviously, grades and attendance rates are available only for the treated group. ${ }^{32}$ Therefore, we reverted the approach previously used to estimate the effects of intentions on actual start-up measures.

In particular, after comparing the baseline characteristics of the two groups with higher and lower human capital ${ }^{33}$ we regressed the grades of the treated group at the end of the course on baseline borrowers' characteristics and then used this model

\footnotetext{
29 See Table 2 for summary statistics and Appendix 4. In principle, the level of education may be considered a more precise measure of human capital, however, poor women in our context show low (and almost no heterogeneous) school attainment rates.

30 See Table 2 for summary statistics.

31 We acknowledge that the first measure may also encompass some forms of diligence. This is the reason that led us to perform the analysis also on the attendance rate (a pure measure of diligence) in order to isolate its contribution to the development of new business ideas and compare it with the role of our proxy of entrepreneurial skills.

32 Mandatory attendance required that women participated to at least $3 / 4$ of the lessons, so there is enough heterogeneity within the group of those mandated to attend.

33 See t-tests for differences in means on these sub-groups in Table A1.6 and additional regressions in Table A1.12 (Appendix 1).
} 
to predict the grades for the overall sample. ${ }^{34}$ Then, as in the previous case, we regressed the actual development of new businesses or products on the predicted grades interacted with the treatment dummy. An analogous model has been adopted to estimate the role of the attendance rate on the setup of new ventures.

The results (Table 6, lower part) indicate that good grades and high attendance tend to increase the likelihood of starting new activities and/or of introducing new products, as suggested by the positive sign and significance of the parameters referred to the interaction between grades and the treatment variable. This confirms that $H 9$ holds, as better educated and more diligent entrepreneurs, end up with taking more effective business decisions (Baklouti 2013; Bhatt and Tang 2002).

\subsection{General assessment and comparison with other studies}

We believe that the context in which our experiment was conducted (greater poverty, illiteracy and lower women's emancipation) may have made the difference in the results of our study, compared to other RCTs (especially Karlan and Valdivia 2011).

In particular, with reference to the household empowerment effects, we obtained an extremely positive response from the course. Indian women, especially those living in the area of Kolkata, are on average less emancipated than elsewhere. Their activities at IIMC, including initiatives related to the microcredit program, are subject to the authorization of the husband. The husbands participated in the experiment (indirectly, but they were also invited to one of the training sessions), trusting the benefits that the course could have provided to their wives and the overall family. Women were allowed, at least initially, to apply the notions learned during the course to their husband's business. Hence, we obtained greater leverage from the point of view of empowerment, compared to previous studies (including $\mathrm{K} \& \mathrm{~V}$ ) conducted in contexts where women's emancipation is already at acceptable levels.

Another element of difference at the institutional level is the more supportive environment provided by IIMC (in particular debt collection mechanism), built on tolerance and persuasion rather than on short-term coercive methods and sanctions.). The consequence of this is that IIMC customers normally experience long delays and are unwilling to accumulate savings. This probably happens to a lesser extent in other contexts due to the incurred penalties. ${ }^{35}$ In our opinion, the course may have helped to compensate for these more lenient policies towards customers, many of whom have realized without the need for coercive rules that delays, loan diversion, and over-indebtedness (a common practice in India) are harmful to them and their households.

Similarly, from the point of view of learning the basic principles of financial management, we obtained more significant results because we operated in a context

\footnotetext{
34 Notice that in the previous case we predicted the intention of implementing new activities and products " $a$ s if" the treated group did not benefit from the training. Here we do the opposite, predicting the grades of the control group "as if" its members participated to the program.

35 In the study of Karlan and Valdivia (2011), for instance, also delays to the training sessions were sanctioned, differently from our experiment.
} 
Table 6 Impact of training-role of potentially successful projects and diligence

\begin{tabular}{lll}
\hline Dependent variable: new business started and/or new product developed & \\
\hline Treatment effects $^{(a)}$ & $(1)$ & $(2)$ \\
Covariates $^{(b)}$ & No & Yes \\
\hline Intention to start a new business (predicted) $^{(\mathrm{c})} *$ treat & $0.587^{* *}(0.237)$ & $0.708^{* *}(0.328)$ \\
Intention to introduce a new product (predicted) $^{(\mathrm{c})} *$ treat & $0.788^{* *}(0.348)$ & $0.892^{*}(0.531)$ \\
Homework evaluation $\left(\right.$ predicted) $^{(\mathrm{d})} *$ treat $^{(\mathrm{d})} *$ treat & $0.068^{* *}(0.026)$ & $0.072^{* *}(0.031)$ \\
Attendance rate $\left(\right.$ predicted) $^{\text {Number of individuals }}$ & $0.315^{*}(0.184)$ & $0.438^{*}(0.238)$ \\
\hline
\end{tabular}

Number of individuals: 172 (81 treated, 91 non-treated). Dependent variable refers to the period March (T2)-June 2010 (T3)

Each coefficient reported in the table corresponds to a separate regression. (a) Reported coefficients (treatment effects) refer to the interaction between the treatment dummy and the predicted values of the variables reported in the leftmost column. Predicted values are obtained applying a linear probability model. (b) Covariates include number of loans, last loan amount, business previously owned by relatives and knowledge of English, and the (non-interacted) variables in the leftmost column. (c) From regressing the dummies "Intention to start a new business" and "Intention to introduce a new product" on the covariates for the non-treated group and extending this model to the treated group to obtain predicted values. (d) From regressing the variables "Homework evaluation" and "Attendance rate" on the covariates for the treated group and extending this model to the control group to obtain predicted values

Robust standard errors in brackets. (*) Significant at 10\%/(**) significant at 5\%/(***) significant at $1 \%$

in which the beneficiaries of the treatment had no knowledge of calculation. It was, therefore, relatively easy to achieve small but significant progress (separation of money from that of business, profit calculation, keeping income-expenditure records).

Other studies, including Karlan and Valdivia (2011), obtain more significant results than us from the point of view of the increase in sales and the general performance of already existing activities. We have no evidence from the point of view of income growth, but we have positive results on the start of new businesses, particularly for some sub-groups of beneficiaries. In our case, the absence of evidence on income may be dictated by the shorter duration of our experiment and the observation period, which may not have fully captured the economic benefits of the course in the long run. The fact that the IIMC women did not conduct any activities before the course may instead explain the greater success in having undertaken new businesses, unlike the women of FINCA who instead probably opted to enhance the activities they already were conducting.

In conclusion, we interpret the effects of training programs like ours as having positive but decreasing returns to scale: if the beneficiaries start from low levels of education, empowerment and wealth, even basic notions can have a strong hold on them, ceteris paribus. 


\section{Extending the pilot experience: net benefits for the institution}

The benefit in terms of reduced payment delays is only one of the benefits of the experiment, and likely a smaller one. However, it may be interesting to quantify them in terms of economic value for IMMC to eventually promote similar programs on a larger scale. In this section, we aim to assess the potential net benefits of extending the training experience conducted with the pilot experiment to all IIMC clients. ${ }^{36}$ We initially assume that the traineeship can be replicated on the universe of IIMC's microcredit clients with constant average benefits equal to those obtained with the pilot RCT. Then we perform a sensitivity analysis specifying how the costs of the program can be adjusted to achieve a zero (or positive) NPV.

In making this evaluation, we combine the results obtained in the empirical analysis illustrated in the previous sections with information gathered at IIMC. In particular, credit managers stressed that standard lending practices at IIMC rarely contemplate "genuine" defaults. As in several other micro-lending programs, discipline is not fostered through punishment strategies but rather using soft-pressure in the form of persuading late payers to fulfil their obligations (Hung 2003; Solli et al. 2015; ***White and Alam 2013).

On the one hand, this allows recovering the full amount due without the need to document defaults on the lender's credit registers, unless defaults and dropouts are a consequence of severe shocks (health, death). On the other hand, soft recovering practices stimulate substantial delay, implying potentially considerable losses due to missing interests and foregone further loans. Therefore, reducing such long delays (rather than minimizing defaults or dropouts) is a very important issue for IIMC, which justifies forms of intervention aimed at fostering higher punctuality and discipline.

We adopt a conservative approach, which considers only the advantages of reducing delays in the amount estimated through the empirical analysis conducted in the previous section, without considering the possible effects of the training program on the decrease of defaults.

The net present value (NPV) of extending the training to all IIMC's clients, estimated as the difference between the present value of the monthly revenues increase and the training costs, is equal to INR - 2,940,074 (about USD - 42,808), i.e., INR -3171 (about USD - 46) per group of 20 women. This implies that $11.91 \%$ $(397,486 / 2,940,074 * 100)$ of the cost of training can be recovered through increased benefits (lower operational costs due to a decreased number of delays).

Given the estimated benefits, extending the training to all IIMC clients would be profitable, i.e., the NPV would be positive, if the costs of the treatment were below INR 428 per group of 20 women (about USD 6). IIMC could achieve this result by reducing the trainers' hourly rate to INR 21.40 (about USD 0.31). ${ }^{37}$ Alternatively,

\footnotetext{
36 Results are reported in Appendix A5, where we also extend the analysis by assuming a decrease in the default rate as an additional outcome of the program.

37 In this exercise, we assumed an hourly wage for the trainers equal to INR 180 (http://www.payscale. com/research/IN/Job=High_School_Teacher/Salary/e177729b/Kolkata).
} 
also increasing the number of attendees per session to 275 women would make it profitable.

Finally, we did not observe a decrease in the default rate, because all loans have been paid off, albeit belatedly. However, because IIMC has a default rate of approximately $2 \%$, we can estimate that even a small decrease in the default rate among late payers, for instance from 2.7 to $2.0 \%$, would allow IIMC to provide the training to all its clients with a profit. We show that a decrease of the default rate by approximately 0.7 percentage points is enough to make the provision of the training to all customers profitable for any initial default rate. ${ }^{38}$

\section{Conclusions and policy implications}

The primary objective of this study was to test the effectiveness of money management and entrepreneurial training course on the beneficiaries of a microcredit program.

Most of the estimated effects are positive and significant, although some teachings provided advantages only to specific categories of beneficiaries, and others did not reach the desired effect. ${ }^{39}$

In line with the previous literature (de Mel et al. 2014; Mano et al. 2012; McKenzie and Woodruff 2014; Valdivia 2015), significant outcomes are found on improved capabilities in separating personal and business finances, maintaining business records, calculating profits, which are the main objectives of the training offered by MFIs to their clients (McKenzie and Woodruff 2014). The estimated effects lasted even more than 3 months after the completion of the course, although a small reduction of the impact was observed in time.

Our study also confirms that these borrowers' positive results are associated with positive outcomes for the MFIs whose clients received the training, as found by other authors (Chowdhury and Mukhopadhaya 2012; Karlan and Valdivia 2011; Ledgerwood 1998). In particular, we found that the number of missing or delayed repayments decreased significantly for the treated borrowers. On the contrary, the course seems not to have produced positive effects on the economic results of the participants. A possible explanation for this result is that microcredit customers cannot improve their economic activity, and the income and expenses of their households, in the short term. In this case, we could observe the effects of better financial management practices only in the medium-long term.

The course empowered the participants both in their families and in their relationships with their peers. In particular, after the course, the women were more active in sharing business experiences with peers and asking for business advice. Therefore, the course seems to have improved the dynamics of microcredit groups, with possible spillover effects. Furthermore, the participants in the course became much more interested in further instruction, with a greater intention to pay for new training. This

\footnotetext{
38 See Appendix 5.

39 A summary of the program achievements is in Appendix 1, Table A1.13.
} 
result suggests that, as long as the opportunity is given, clients of microcredit are interested in raising their level of education. Only minor improvements are observed on the entrepreneurial side, such as starting new entrepreneurial activities or introducing new products.

However, the small size of the experiment allowed for more detailed tracking of participants' course performance. We were able to identify and exploit relevant heterogeneities among the borrowers, thus adding new insights on the effects of entrepreneurial training.

In particular, we found that women with higher human capital were more likely to start new businesses or undertook the development of new products. Our estimates also provide evidence that the training helped the attendees who already had an entrepreneurial idea to develop before the course to experience significant changes in their business activities.

Other objectives of the research included measuring the effectiveness of the course on voluntary and non-voluntary members, and on members with high or low interest in a training course. On the one hand, participants for whom the attendance was compulsory took much more advantage than volunteers from participation in the course. On the other hand, participants who at the beginning of the course had a relatively high interest in entrepreneurial training obtained more significant improvements in several skills and institutional outcomes.

Another original finding of our analysis, stemming from contemporaneously considering compulsory attendance and interest in training, is that the willingness to participate in a costly training (high interest) seems to overcome the difference in impact between the women mandated to attend and the volunteers. The most significant effects are observed on financial management variables, and household non-economic variables, such as taking decisions within the household and working with the husband. It is also noticeable that those who showed more interest in the course also significantly reduced the number of delayed payments. Therefore, mandatory participation does not seem to be a key factor in determining the success of the program. Rather, it is advisable that lenders also consider the interest shown by women in learning financial practices when selecting participants for financial literacy programs.

However, considering the interpretation of attendance at training as an improvement in the effectiveness of training at this stage of the experiment, caution should be exercised. Many external factors can influence presence, including family support and independence of participants, the number of young children, health and so on. The reader should therefore interpret these estimates as intent-to-treat estimates as some members of the treatment have the opportunity to train. Choosing how much to participate can mediate the effect of training. But this should not indicate that training is more effective for those who are devoted enough to participate.

Overall, the results of this study confirm that training based on a simple, ruleof-thumb approach, and delivered to women with no entrepreneurial skills and high illiterate rates could improve their financial practices, as found by Drexler et al. (2014). In particular, this kind of training can be effective in encouraging them to maintain business records and to separate household and business finances 
(McKenzie and Woodruff 2014), provided that the teaching contents are scaled down to effectively match the extremely low literacy rate of the beneficiaries.

Finally, improved financial practices are associated with a considerable reduction of repayment delays. Bundling training modules to microfinance programs, and/or getting borrowers involved both in teaching and learning, could help to obtain more tangible improvements and save on organizational expenses. Further research may concern a careful design of the contents, fees, incentives, and rewards for the scaling up of training experiences such as the one described in this study.

Supplementary Information The online version contains supplementary material available at https://oi. org/10.1007/s40888-021-00217-9.

Funding Open Access funding provided by Università degli Studi di Milano - Bicocca.

Open Access This article is licensed under a Creative Commons Attribution 4.0 International License, which permits use, sharing, adaptation, distribution and reproduction in any medium or format, as long as you give appropriate credit to the original author(s) and the source, provide a link to the Creative Commons licence, and indicate if changes were made. The images or other third party material in this article are included in the article's Creative Commons licence, unless indicated otherwise in a credit line to the material. If material is not included in the article's Creative Commons licence and your intended use is not permitted by statutory regulation or exceeds the permitted use, you will need to obtain permission directly from the copyright holder. To view a copy of this licence, visit http://creativecommons.org/licen ses/by/4.0/.

\section{References}

Aagaard, P. (2011). The global institutionalization of microcredit. Regulation and Governance, 5(4), $465-479$.

Afandi, E., Kermani, M., \& Mammadov, F. (2017). Social capital and entrepreneurial process. International Entrepreneurship and Management Journal, 13(3), 685-716. https://doi.org/10.1007/s1136 5-016-0421-8.

Afrin, S., Islam, N., \& Ahmed, S. U. (2008). A multivariate model of micro credit and rural women entrepreneurship development in Bangladesh. International Journal of Business and Management, $3(8), 169-185$.

Alam, S. (2012). The effect of gender-based returns to borrowing on intra-household resource allocation in rural Bangladesh. World Development, 40(6), 1164-1180.

Angelucci, M., Karlan, D. S., \& Zinman, J. (2015). Microcredit impacts: Evidence from a randomized microcredit program placement experiment by compartamos Banco. American Economic Journal Applied Economics, 7(1), 151-182.

Angrist, J. D., \& Pischke, J. (2008). Mostly harmless econometrics: An empiricist's companion. Princeton: Princeton University Press.

Armendáriz de Aghion, B., \& Morduch, J. (2005). The economics of microfinance. Cambridge: The MIT Press.

Attanasio, O., Augsburg, B., De Haas, R., Fitzsimons, E., \& Harmgart, H. (2015). The impacts of microfinance: Evidence from joint-liability lending in Mongolia. American Economic Journal Applied Economics, 7(1), 90-122.

Augsburg, B., De Haas, R., Harmgart, H., \& Meghir, C. (2015). The impacts of microcredit: Evidence from Bosnia and Herzegovina. American Economic Journal Applied Economics, 7(1), 183-203.

Baklouti, I. (2013). Determinants of microcredit repayment: The case of Tunisian Microfinance Bank. African Development Review, 25(3), 370-382.

Banerjee, A. V., Duflo, E., \& Glennerster, R. (2015). The miracle of microfinance? Evidence from a randomized evaluation. American Economic Journal Applied Economics, 7(1), 22-53. 
Bauer, M., Chytilová, J., \& Morduch, J. (2012). Behavioral foundations of microcredit: Experimental and survey evidence from rural India. American Economic Review, 102(2), 1118-1139.

Benzing, C., Chu, H. M., \& Bove, R. (2005b). The motivation, problems, and perceived success of entrepreneurs in Romania. Journal of the Academy of Business Administration, $10(1$ \& 2), 73-88.

Benzing, C., Chu, H. M., \& Callanan, G. (2005a). A regional comparison of the motivation and problems of Vietnamese entrepreneurs. Journal of Developmental Entrepreneurship, 10(1), 3-27.

Benzing, C., Chu, H. M., \& Kara, O. (2009). Entrepreneurs in Turkey: A factor analysis of motivations, success factors, and problems. Journal of Small Business Management, 47(1), 58-91.

Benzing, C., Chu, H. M., \& Szabo, B. (2005c). Hungarian and Romanian Entrepreneurs in Romaniamotivation, problems, and differences. Journal of Global Business, 16, 77-82.

Berge, L. I. O., Bjorvatn, K., \& Tungodden, B. (2015). Human and financial capital for microenterprise development: Evidence from a field and lab experiment. Management Science, 61(4), 707-722. https://doi.org/10.1287/mnsc.2014.1933.

Bhatt, N., \& Tang, S.-Y. (2002). Determinants of repayment in microcredit: Evidence from programs in the United States. International Journal of Urban and Regional Research, 26(2), 360-376.

Bjorvatn, K., \& Tungodden, B. (2010). Teaching business in Tanzania: Evaluating participation and performance. Journal of the European Economic Association, 8(2-3), 561-570.

Brau, J. C., \& Woller, G. M. (2004). Microfinance: A comprehensive review of the existing literature. Journal of Entrepreneurial Finance and Business Ventures, 9(1), 1-26.

Bruhn, M., Karlan, D., \& Schoar, A. (2010). What capital is missing in developing countries? American Economic Review, 100(2), 629-633.

Bruhn, M., \& Zia, B. (2013). Stimulating managerial capital in emerging markets: The impact of business training for young entrepreneurs. Journal of Development Effectiveness, 5(2), 232-266.

Bruton, G., Khavul, S., Siegel, D., \& Wright, M. (2015). New financial alternatives in seeding entrepreneurship: Microfinance, crowdfunding, and peer-to-peer innovations. Entrepreneurship Theory and Practice, 39(1), 9-26.

Cajiao, J., \& Burke, M. J. (2016). How instructional methods influence skill development in management education. Academy of Management Learning and Education, 15(3), 508-524. https://doi. org/10.5465/amle.2013.0354.

Chowdhury, T. A., \& Mukhopadhaya, P. (2012). Assessment of multidimensional poverty and effectiveness of microfinance-driven government and NGO projects in the rural Bangladesh. The Journal of Socio-Economics, 41(5), 500-512.

Chu, H. M., Benzing, C., \& McGee, C. (2007). Ghanaian and Kenyan entrepreneurs: A comparative analysis of their motivations, success characteristics and problems. Journal of Developmental Entrepreneurship, 12(3), 295-322.

Churchill, C. (2002). Trying to understand the demand for microinsurance. Journal of International Development, 14, 381-387.

Cohen, J. (1965). Some statistical issues in psychological research. In B. B. Wolman (Ed.), Handbook of clinical psychology (pp. 95-121). New York: McGraw-Hill.

Cook, R. G., Belliveau, P., \& Von Seggern, K. L. (2001). A case study of microenterprise training: Beta test findings and suggestions for improvement. Journal of Developmental Entrepreneurship, 6, 255-267.

Copestake, J. (2007). Mainstreaming microfinance: Social performance management or mission drift? World Development, 35(10), 1721-1738.

Coppock, D. L., Desta, S., Tezera, S., \& Gebru, G. (2011). Capacity building helps pastoral women transform impoverished communities in Ethiopia. Science, 334(6061), 1394-1398.

Crépon, B., Devoto, F., Duflo, E., \& Parienté, W. (2015). Estimating the impact of microcredit on those who take it up: Evidence from a randomized experiment in Morocco. American Economic Journal Applied Economics, 7(1), 123-150.

de Mel, S., McKenzie, D., \& Woodruff, C. (2014). Business training and female enterprise start-up, growth, and dynamics: Experimental evidence from Sri Lanka. Journal of Development Economics, 106, 199-210. https://doi.org/10.1016/j.jdeveco.2013.09.005.

Drexler, A., Fischer, G., \& Schoar, A. (2014). Keeping it simple: Financial literacy and rules of thumb. American Economic Journal Applied Economics, 6(2), 1-31.

Dumas, C. (2001). Evaluating the outcomes of microenterprise training for low income women: A case study. Journal of Developmental Entrepreneurship, 6, 97-129.

Edgcomb, E. L. (2002). What makes for effective microenterprise training? Journal of Microfinance, $4(1), 99-114$. 
Evans, T. G., Adams, A. M., Mohammed, R., \& Norris, A. H. (1999). Demystifying nonparticipation in microcredit: A population-based analysis. World Development, 27(2), 419-430.

Eversole, R. (2003). Help, risk and deceit: Microentrepreneurs talk about microfinance. Journal of International Development, 15(2), 179-188.

Fagley, N. S. (1985). Applied statistical power analysis and the interpretation of nonsignificant results by research consumers. Journal of Counseling Psychology, 32(3), 391-396.

Fagley, N. S., \& McKinney, I. J. (1983). Reviewer bias for statistically significant results: A reexamination. Journal of Counseling Psychology, 30(2), 298-300.

Feigenberg, B., Field, E. M., \& Pande, R. (2013). The economic returns to social interaction: Experimental evidence from microfinance. The Review of Economic Studies, 80(4), 1459-1483.

Field, E. M., Jayachandran, S., \& Pande, R. (2010). Do traditional institutions constrain female entrepreneurship? A field experiment on business training in India. American Economic Review, 100(2), 125-129.

Garaus, C., Furtmüller, G., \& Güttel, W. H. (2016). The hidden power of small rewards: The effects of insufficient external rewards on autonomous motivation to learn. Academy of Management Learning and Education, 15(1), 45-59. https://doi.org/10.5465/amle.2012.0284.

Giné, X., \& Mansuri, G. (2014). Money or ideas? A field experiment on constraints to entrepreneurship in Rural Pakistan. IMF Policy Research Working Paper, 6959.

Godquin, M. (2004). Microfinance repayment performance in Bangladesh: How to improve the allocation of loans by MFIs. World Development, 32(11), 1909-1926.

Guinnane, T. W. (2011). The early German credit cooperatives and microfinance organizations today: Similarities and differences. In B. Armendáriz de Aghion \& M. Labie (Eds.), The handbook of microfinance (pp. 77-100). Singapore: World Scientific Publishing.

Hartarska, V., \& Parmeter, C. (2009). Scope Economies of Lending and Collecting Deposits in Microfinance Institutions. http://ageconsearch.umn.edu/bitstream/51799/2/605 IAAE 09 scope economies in microfinance.pdf

Hermes, N., \& Lensink, R. (2011). Microfinance: Its impact, outreach, and sustainability. World Development, 39(6), 875-881.

Holvoet, N. (2005). The impact of microfinance on decision-making agency: Evidence from South India. Development and Change, 36(1), 75-102.

Huang, L.-S. (2003). Ten pointers for enhancing learners' motivation. Business Communication Quarterly, 66(4), 88-95. https://doi.org/10.1177/108056990306600409.

Hung, C. R. (2003). Loan performance of group-based microcredit programs in the United States. Economic Development Quarterly, 17(4), 382-395.

Imai, K. S., Gaiha, R., Thapa, G., \& Annim, S. K. (2012). Microfinance and poverty-a macro perspective. World Development, 40(8), 1675-1689.

Karlan, D. S., \& Valdivia, M. (2011). Teaching entrepreneurship: Impact of business training on microfinance clients and institutions. Review of Economics and Statistics, 93(2), 510-527.

Karlan, D. S., \& Zinman, J. (2011). Microcredit in theory and practice: Using randomized credit scoring for impact evaluation. Science, 332, 1278-1284.

Khan, M. A., \& Ali, A. J. (2014). The role of training in reducing poverty: The case of the ultra-poor in Bangladesh. International Journal of Training and Development, 18(4), 271-281. https://doi. org/10.1111/ijtd.12041.

Krishnaswamy, K. (2007). Competition and multiple borrowing in the Indian microfinance sector. Institute for Financial Management and Research Centre for Micro Finance Working Papers.

Ledgerwood, J. (1998). Microfinance handbook: An institutional perspective. Washington, DC: The International Bank for Reconstruction and Development-The World Bank.

Mahmud, K. T., Parvez, A., Hilton, D., Kabir, G. M. S., \& Wahid, I. S. (2014). The role of training in reducing poverty: The case of agricultural workers receiving microcredit in Bangladesh. International Journal of Training and Development, 18(4), 282-290. https://doi.org/10.1111/ijtd.12039.

Mahmud, S. (2003). Actually how empowering is microcredit? Development and Change, 34(4), 577-605.

Mano, Y., Iddrisu, A., Yoshino, Y., \& Sonobe, T. (2012). How can micro and small enterprises in SubSaharan Africa become more productive? The impacts of experimental basic managerial training. World Development, 40(3), 458-468.

Mata, R. S. (2006). Savings in microfinance institutions: From mobilisation to financial sustainability. Case of the Ecuadorian COAC 4 de Octubre. 
Mayoux, L. (2001). Tackling the down side: Social capital, women's empowerment and micro-finance in Cameroon. Development and Change, 32(3), 435-464.

McKenzie, D. (2012). Beyond baseline and follow-up: The case for more $\mathrm{T}$ in experiments. Journal of Development Economics, 99(2), 210-221.

McKenzie, D., \& Woodruff, C. (2014). What are we learning from business training and entrepreneurship evaluations around the developing world? The World Bank Research Observer, 29(1), 48-82.

Mirpourian, S., Caragliu, A., Di Maio, G., Landoni, P., \& Rusinà, E. (2016). Determinants of loan repayment performance among borrowers of microfinance institutions: Evidence from India. World Development Perspectives, 1, 49-52.

Morduch, J. (1999). The microfinance promise. Journal of Economic Literature, 37(4), 1569-1614.

Mortensen, J., Seawright, K., Bott, M., Mai, Q., \& Badger, J. (2005). Entrepreneurial development in the informal economy: In search of sustainable entrepreneurial development. http://marriottschool.byu. edu/selfreliance/workingpapers/library/995.doc.

Neal, M. (2017). Learning from poverty: Why business schools should address poverty, and how they can go about it. Academy of Management Learning and Education, 16(1), 54-69. https://doi. org/10.5465/amle.2014.0369.

Ngo, T.M.-P., \& Wahhaj, Z. (2012). Microfinance and gender empowerment. Journal of Development Economics, 99(1), 1-12.

Noe, R. A. (1986). Trainees' attributes and attitudes: Neglected influences on training effectiveness. The Academy of Management Review, 11(4), 736-749.

Pallant, J. (2001). SPSS survival manual: A step-by-step guide to data analysis using SPSS for windows (Version 10). Philadelphia: Open University Press.

Poggesi, S., Mari, M., \& De Vita, L. (2016). What's new in female entrepreneurship research? Answers from the literature. International Entrepreneurship and Management Journal, 12(3), 735-764. https ://doi.org/10.1007/s11365-015-0364-5.

Pujari, Y. D. (2011). Rural indebtedness: Causes and consequences. Indian Streams Research Journal, $1(1), 124-127$.

Rajeev, M., Vani, B. P., \& Bhattacharjee, M. (2012). Nature and dimensions of farmers' indebtedness in India and Karnataka. Institute for Social and Economic Change Working Paper Series, 267.

Roslan, A. H., \& Karim, M. Z. A. (2009). Determinants of microcredit repayment in Malaysia: The case of Agrobank. Humanity and Social Sciences Journal, 4(1), 45-52.

Saeed, S., \& Zyngier, D. (2012). How motivation influences student engagement: A qualitative case study. Journal of Education and Learning, 1(2), 252-267. https://doi.org/10.5539/jel.v1n2p252.

Sajjad, H., \& Chauhan, C. (2012). Agrarian distress and indebtedness in rural India: Emerging perspectives and challenges ahead. Journal of Geography and Regional Planning, 5(15), 397-408.

Sawyer, A. G., \& Ball, A. D. (1981). Statistical power and effect size in marketing research. Journal of Marketing Research, 18(3), 275-290.

Sayinzoga, A., Bulte, E. H., \& Lensink, R. (2016). Financial literacy and financial behaviour: Experimental evidence from rural Rwanda. Economic Journal, 126(594), 1571-1599. https://doi.org/10.1111/ ecoj.12217.

Solli, J., Galindo, L., Rizzi, A., Rhyne, E., \& van de Walle, N. (2015). What happens to microfinance clients who default? An exploratory study of microfinance practices. The Smart Campaign. http:// www.smartcampaign.org/storage/documents/what_happens_to_microfinance_clients_who_defau lt_eng.pdf

Tarozzi, A., Desai, J., \& Johnson, K. (2015). The impacts of microcredit: Evidence from Ethiopia. American Economic Journal Applied Economics, 7(1), 54-89.

Valdivia, M. (2015). Business training plus for female entrepreneurship? Short and medium-term experimental evidence from Peru. Journal of Development Economics, 113, 33-51.

White, R., \& Alam, S. A. (2013). Asset ownership and microloan repayment: Examining data from Bangladesh. Development Policy Review, 31(3), 343-368.

Williams, K. C., \& Williams, C. C. (2011). Five key ingredients for improving student motivation. Research in Higher Education Journal, 12, 1-23. http://aabri.com/manuscripts/11834.pdf.

Yunus, M. (2004). Grameen Bank, Microcredit and Millennium Development Goals. Economic and Political Weekly, (September 4), 4077-4080.

Publisher's Note Springer Nature remains neutral with regard to jurisdictional claims in published maps and institutional affiliations. 